DOI: $10.15593 / 2224-9354 / 2020.2 .22$

УДК 005.8:61-048.35

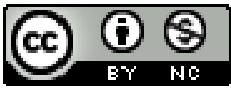

\author{
Е.Ю. Бикметов, 3.Ж. Гумерова, И.Я. Рувенный
}

\author{
СОЦИАЛЬНО ОРИЕНТИРОВАННЫЙ МАРКЕТИНГ \\ В УПРАВЛЕНИИ ПРОЕКТАМИ ВЫСОКОТЕХНОЛОГИЧНЫХ \\ МЕДИЦИНСКИХ ИННОВАЦИЙ
}

\begin{abstract}
Актуализируется необходимость маркетингового управления проектами как инструмента инновационного развития российского здравоохранения. Исследование базируется на концепции социально ориентированного маркетинга и интеграции усилий медицины, науки, бизнеса, государственного управления. Одним из способов сокращения длительности этапа вывода на рынок инноваций в сфере высокотехнологичной медицины авторам видится научно планируемое и организуемое социально ориентированное маркетинговое управление инновационными проектами в сфере здравоохранения. Обоснована применимость подхода маркетинга взаимоотношений в сфере здравоохранения; раскрыты особенности и риски поэтапного маркетингового обеспечения управления проектами в сфере высокотехнологичной медицины; определены возможности коллаборации участников в их реализации. Акцентирование внимания на взаимоотношениях следует рассматривать как важную предпосылку социально ориентированного маркетингового управления инновационными проектами. Управление медицинскими проектами, основанное на маркетинге взаимоотношений, необходимо дополнить механизмом государственно-частного партнерства для усиления синергетического эффректа. Для конкретизации предлагаемого инструмента исследуются особенности и риски этапов маркетингового обеспечения управления проектами в сфере высокотехнологичной медицины. Обоснован вывод, что социально ориентированный, клиентоцентрированный маркетинговый подход к инновационным медицинским проектам невозможно реализовать без государственного присутствия в качестве активного регулятора рыночных отношений в сфере здравоохранения. Ориентация в коллаборации государства, некоммерческих организаций, бизнеса на сохранение здоровья и трудоспособности населения способствует обеспечению конкретного человека и социальных групп населения медицинскими товарами и услугами. Результаты исследования позволяют снизить уровень дискуссионности вопроса о маркетинговом управлении проектами в области медицинских инноваций и повысить эффективность принимаемых управленческих решений в этом направлении, что в итоге способно привести к увеличению количества и повышению качества реализованных инновационных проектов.

Ключевые слова: управление инновационным проектом, высокотехнологичные медицинские товары и услуги, здравоохранение, социально ориентированный маркетинг, маркетинг взаимоотношений, клиентоцентрированность, государственно-частное партнерство.
\end{abstract}

(с) Бикметов Е.Ю., Гумерова З.Ж., Рувенный И.Я., 2020

Бикметов Евгений Юрьевич - д-р социол. наук, профессор кафедры менеджмента и маркетинга ФГБОУ ВО «Уфимский государственный авиационный технический университет», гл. науч. сотрудник Института социально-экономических исследований Уфимского федерального исследовательского центра РАH, e-mail: bicprof@mail.ru.

Гумерова Зиляра Жановна - канд. экон. наук, доцент кафедры менеджмента и маркетинга ФГБОУ ВО «Уфимский государственный авиационный технический университет», e-mail: lapa28@ramblerl.ru.

Рувенный Игорь Ярославович - канд. экон. наук, завкафедрой менеджмента и маркетинга ФГБОУ ВО «Уфимский государственный авиационный технический университет», e-mail: ruvenny@mail.ru. 
Необходимость создания эффективной управленческой модели в сфере здравоохранения актуализирована в принятой «Стратегии развития здравоохранения в Российской Федерации на период до 2025 года» [1]. В качестве цели политики государства в сфере здравоохранения определено достижение возможности получения медицинской помощи и рост результативности медицинских услуг. Однако в настоящее время оснащенность российских учреждений здравоохранения (особенно бюджетных и автономных) медицинской техникой ограничивает уровень удовлетворения потребностей населения в медицинской помощи. Такая ситуация во многом обусловлена, по мнению авторов, несовершенством работы маркетинговых служб предприятий медицинской промышленности; неразвитостью каналов снабжения и сервисного обслуживания медицинского оборудования; отсутствием методологии маркетинговой стратегии разработки и внедрения инновационных медицинских проектов.

Задачами настоящего исследования выступают:

- обоснование применимости концепции маркетинга отношений в сфере здравоохранения;

- планирование и организация социально ориентированного маркетингового управления инновационными проектами;

- определение возможностей коллаборации (партнерств, объединений потенциалов) для обеспечения синергетического эффекта реализации проектов высокотехнологичных медицинских инноваций.

Решение поставленных задач позволит повысить результативность маркетингового управления проектами в сфере высокотехнологичной медицины. В отечественной [2-8] и зарубежной [9-15] научной литературе, посвященной рассматриваемой теме, предлагаются основные маркетинговые принципы управления в здравоохранении, исследуются составляющие компоненты медицинского маркетингового комплекса, раскрываются сущность, задачи социально ориентированного маркетинга, предлагаются методы оценки эффективности программ здравоохранения [16]. Однако в исследованиях не получила достаточного раскрытия и решения проблема социально ориентированного маркетингового управления проектами внедрения инноваций в сфере высокотехнологичной медицины. Сохраняется дискуссионность вопроса о необходимости применения инструментов маркетинга в области медицинских инноваций.

Настоящее исследование опирается на следующие методологические принципы, использование которых позволило сформулировать основные результаты исследования с учетом всех значимых внешних и внутренних факторов, определяющих эффективность медицинских инновационных проектов:

- принцип системности, позволяющий целостно рассмотреть характер и механизм отношений между всеми участниками медицинских инновационных проектов;

- принцип сущностного анализа, связанный с раскрытием законов существования и развития сложных социально-экономических систем и ключевых факторов их развития, возможности их целенаправленного изменения. 
В проведенном исследовании использованы следующие методы и концепции:

1) методы системного и логического анализа, позволившие учесть и эффективно использовать разнообразные по характеру, форме и объему данные, полученные в процессе анализа первичной и вторичной информации;

2) прикладные методы социологического и маркетингового исследования, в том числе наблюдение, опрос целевых групп (в том числе экспертный) - участников процесса медицинской услуги (пациенты, врачи, менеджеры лечебных учреждений, работники министерства здравоохранения Республики Башкортостан) и процесса разработки инновации в сфере здравоохранения (ученые и преподаватели Башкирского государственного медицинского университета, ученые-инженеры Уфимского государственного авиационного технического университета, инженеры и менеджеры предприятий-производителей изделий медицинского назначения для остеосинтеза и ортопедии, инвесторы, чиновники министерства здравоохранения Республики Башкортостан);

3) статистический анализ базы данных экспортно-импортных операций РФ по изделиям медицинского назначения за 2013-2018 гг.;

4) интегративный подход, способствующий объединению разнородных компонентов систем при решении инновационных задач в сфере здравоохранения и исключению на основе выбора интегрирующего основания потенциально возможной разобщенности науки и техники, медицины, органов власти и инвесторов;

5) концепция «маркетинга отношений», ориентированная на партнерское управление отношениями всех участников инновационных проектов, направленное на удовлетворение социальных потребностей общества [17-19].

Существуют определенные препятствия в применении указанных концепций в маркетинге инновационных проектов в сфере здравоохранения, к которым следует отнести первичное недоверие пациентов к медицинским инновациям; высокий уровень эмоциональной вовлеченности при принятии решения, что часто ведет к субъективизму; наличие жестких нормативных стандартов оказания ряда медицинских услуг.

По мнению авторов, управление проектами, основанное на маркетинге взаимоотношений, необходимо дополнить механизмом государственночастного партнерства (ГЧП) для усиления синергетического эффекта. Интеллектуально-культурный капитал организации первостепенно влияет на создание социально ориентированных организационных структур управления, служащих гарантией социальной и правовой ответственности участников организации, развитие межсекторальных партнерских отношений. Построение отношений государства и бизнеса на взаимовыгодных условиях базируется на совместном использовании ресурсного потенциала. Такое партнерство предполагает реализацию преимуществ государственного сектора (наличие функ- 
ции регулирования, правомочия собственника) и частного сектора (стратегические ресурсы, ноу-хау, профессиональные компетенции, управленческий потенциал) в интересах достижения реальных позитивных инновационных результатов в сфере здравоохранения. Методологической основой построения и реализации проектов государственно-частного партнерства выступает идея «устойчивого развития» (Дж. Элкингтон, Г. Йонас и др.) [20, 21]. Хозяйственную деятельность производителей, их взаимодействие с органами власти и управления, лечебными учреждениями следует рассматривать с позиции устойчивого развития, которое ориентируется на удовлетворение потребностей сегодняшнего поколения людей без угрозы удовлетворению нужд следующих поколений. При этом ориентация на технологический прогресс (цифровизацию экономики) и институциональные изменения соответствует балансу потребностей будущего и настоящего. ГЧП может способствовать позиционированию России в мире как нового центра оказания высокотехнологичных медицинских услуг по следующим направлениям: поддержка программ развития ведущих российских клинических центров на основе принципов ГЧП, обеспечение высокого качества сервисной составляющей медицинских услуг на условиях ГЧП, внедрение новых форм организации управления, в том числе с использованием социально ориентированного маркетинга. Привлечение средств в здравоохранение из частных источников позволяет пополнить материально-техническую базу современным оборудованием, привлечь в медицину новые технологии, квалифицированные кадры, обеспечить необходимый уровень клиентоцентрированности. Для повышения эффективности реализации механизмов ГЧП на региональном уровне целесообразно осуществить стандартизацию схемы сопровождения и реализации проектов ГЧП с учетом региональной специфики и обеспечить организационное сопровождение с помощью введения должности координатора по вопросам ГЧП в штатное расписание региональных органов власти [22, с. 133].

Под инновацией в сфере высокотехнологичной медицины понимается изделие или услуга медицинского назначения, которые приобретаются для использования квалифицированным медицинским персоналом для оказания услуг медицинского характера. Кроме того, из-за существенных последствий и влияния медицинских инноваций на здоровье, а иногда и жизнь человека, этап внедрения инноваций в этой сфере связан с законодательным и нормативным регулированием и длительными периодами времени. Вследствие этого возникают особенности на каждом этапе маркетингового сопровождения инновационного проекта от зарождения идеи инновации до ее продвижения на рынок сбыта. Без учета этих особенностей невозможно обеспечить эффективность применения инструментов маркетинга и соответственно обеспечить результативность инновационного медицинского проекта в целом.

Одним из способов сокращения длительности этапа вывода на рынок инноваций в сфере высокотехнологичной медицины авторам видится научно 
планируемое и организуемое социально ориентированное маркетинговое управление инновационными проектами в сфере здравоохранения. Обоснованию алгоритма оценки и выбора инновационных проектов посвящено отдельное исследование, результаты которого авторами были опубликованы ранее [23]. Такое управление инновационными проектами позволит обеспечить снижение вероятности и уровня значимости рисков на каждом этапе, что в свою очередь обеспечит рост социально-экономических результатов реализации проектов. Авторы полагают, что количество, последовательность и содержание этапов маркетинга инновационных проектов в сфере высокотехнологичной медицины имеют свои особенности. Обобщение практического опыта подготовки и реализации инновационных проектов позволило выявить содержание каждого этапа маркетингового сопровождения, оценить влияние этапов на характер рисков проекта и установить приоритеты в осуществлении маркетинговых мероприятий и инструментов, направленных на снижение этих рисков (таблица).

Особенности и риски этапов маркетингового обеспечения управления проектами в сфере высокотехнологичной медицины*

\begin{tabular}{|c|c|c|}
\hline $\begin{array}{l}\text { Этап маркетинго- } \\
\text { вого обеспечения }\end{array}$ & Содержание этапа & Риски этапа \\
\hline $\begin{array}{c}\text { Анализ марке- } \\
\text { тинговой среды } \\
\text { изделия меди- } \\
\text { цинского назна- } \\
\text { чения }\end{array}$ & $\begin{array}{l}\text { Тестирование и исследования для повыше- } \\
\text { ния шансов коммерческой успешности } \\
\text { нового вида продукта на стадии разработ- } \\
\text { ки. Учет последствий нововведений для } \\
\text { конкретного человека и населения в целом } \\
\text { на длительную перспективу в условиях } \\
\text { высокого уровня неопределенности из-за } \\
\text { отсутствия аналогов. Учет высоких психо- } \\
\text { логических барьеров восприятия иннова- } \\
\text { ционной продукции }\end{array}$ & $\begin{array}{l}\text { Маркетинговый (риск } \\
\text { ошибочного выбора } \\
\text { инновационного проек- } \\
\text { та, риск ошибочной } \\
\text { оценки рынка потреб- } \\
\text { ления). } \\
\text { Экономический (рост } \\
\text { расходов на маркетин- } \\
\text { говые исследования) }\end{array}$ \\
\hline $\begin{array}{c}\text { Исследование } \\
\text { потребностей } \\
\text { врачей, админи- } \\
\text { страции меди- } \\
\text { цинских учреж- } \\
\text { дений и медицин- } \\
\text { ских чиновников }\end{array}$ & $\begin{array}{l}\text { Сочетание интересов всех сторон процесса } \\
\text { разработки, продвижения и использования } \\
\text { высокотехнологичной инновации. Исполь- } \\
\text { зование актуальных и авторитетных дово- } \\
\text { дов для профессионалов медицинской сфе- } \\
\text { ры. Вовлечение потребителей (врачей) в } \\
\text { создание новых продуктов, раннее их зна- } \\
\text { комство с новинкой }\end{array}$ & $\begin{array}{l}\text { Конкурентный (риск } \\
\text { утечки конфиденциаль- } \\
\text { ной информации). } \\
\text { Этический (ограниче- } \\
\text { ния при проведении } \\
\text { доклинических и кли- } \\
\text { нических испытаний) }\end{array}$ \\
\hline $\begin{array}{c}\text { Планирование } \\
\text { цены инновации }\end{array}$ & $\begin{array}{l}\text { Высокий уровень цены инноваций из-за } \\
\text { существенных затрат на этапе фундамен- } \\
\text { тальных и поисковых исследований, что } \\
\text { может сделать инновацию неконкуренто- } \\
\text { способной }\end{array}$ & $\begin{array}{l}\text { Экономический } \quad \text { (риск } \\
\text { непредвиденных затрат } \\
\text { и увеличения цены ин- } \\
\text { новации) }\end{array}$ \\
\hline
\end{tabular}


Окончание таблицы

\begin{tabular}{|c|c|c|}
\hline $\begin{array}{l}\text { Этап маркетинго- } \\
\text { вого обеспечения }\end{array}$ & Содержание этапа & Риски этапа \\
\hline $\begin{array}{c}\text { Планирование } \\
\text { распределения } \\
\text { инновации }\end{array}$ & $\begin{array}{l}\text { Учет политико-правовых, экономических, } \\
\text { социокультурных, технологических и от- } \\
\text { раслевых факторов внешней среды: требо- } \\
\text { вания законодательства при определении } \\
\text { схем поставок медицинских изделий, де- } \\
\text { мографические тенденции, экономическая } \\
\text { ситуация в регионе, наличие инфраструк- } \\
\text { туры под конкретную медицинскую инно- } \\
\text { вацию, наличие заменителей и т.п. }\end{array}$ & $\begin{array}{l}\text { Правовой (риск нару- } \\
\text { шения требований фе- } \\
\text { деральных законов Ф3 - } \\
44 \text { и ФЗ-223). } \\
\text { Экономический (риск } \\
\text { необеспечения иннова- } \\
\text { ционного проекта дос- } \\
\text { таточным уровнем фи- } \\
\text { нансирования) }\end{array}$ \\
\hline $\begin{array}{l}\text { Информационно- } \\
\text { коммуникацион- } \\
\text { ное продвижение } \\
\text { инновации }\end{array}$ & $\begin{array}{l}\text { Существенная роль коммуникационной } \\
\text { составляющей маркетинга на прединве- } \\
\text { стиционной, инвестиционной и эксплуата- } \\
\text { ционной фазах реализации проекта }\end{array}$ & $\begin{array}{l}\text { Маркетинговый (риск } \\
\text { проведения неэффек- } \\
\text { тивного продвижения } \\
\text { инновации) }\end{array}$ \\
\hline
\end{tabular}

*Основано на результатах исследований авторского коллектива.

Учитывая особую роль информационно-коммуникационного сопровождения управления маркетингом высокотехнологичных медицинских инноваций, рассмотрим данный этап маркетингового сопровождения подробнее. Решение проблемы эффективности информационного взаимодействия авторам видится в активизации применения такого средства коммуникационной поддержки инновационного проекта, как PR. Если приоритетным является комплексное продвижение медицинского проекта на рынке В2В, то акцент делается на управление репутацией и формирование доверия общественности. Разработка программы PR-деятельности в маркетинге медицинских проектов на В2В рынке ставит своей целью систематизацию информационно-пропагандистских мероприятий, направленных на улучшение информационного обеспечения, создание положительного имиджа, большей привлекательности для инвесторов и органов власти. Для решения задач PR-обеспечения проекта необходимы усилия по следующим направлениям: публикации в специализированных медицинских СМИ; регулярные встречи руководителей и участников проекта с представителями СМИ; ежеквартальное проведение пресс-конференций на базе информационных агентств; участие в конференциях и «круглых столах» совместно с заказчиками и другими стейкхолдерами; активизация выставочной деятельности; работа по информационному наполнению внешнего web-сайта проекта; размещение в блогах следующих сообщений: совместные кейсы с клиентами (разбор ситуации до и после сотрудничества); мнение экспертов о событиях в отрасли; аналитические обзоры (обоснованная точка зрения на будущее отрасли); рейтинги (определение уникальности подрядчиков); ответы на актуальные вопросы; анонсы мероприятий; издание книг, буклетов, проспектов, другой информационно-рекламной литературы; позиционирова- 
ние самих руководителей и участников проекта; организация «гула клиентов» [24, с. 19-20]; поддержка и работа с экспертным мнением.

Проектная деятельность, как известно, сопряжена с построением новых моделей социально-экономических объектов и процессов, реорганизаций старых организационных форм и структур, позволяющих реализовать принцип коллегиальности и партнерства. Создание такого рода практик не может производиться лишь менеджерами, чиновниками. Данная стратегическая задача связана с социальной составляющей проектной деятельности, направленной на трансформацию установок производителей и посредников в сторону социальной ответственности и клиентоцентрированности в маркетинговой политике, предполагающей инкорпорирование профессиональных и других групп общественности в деловое сотрудничество по созданию конкретных образов будущего объекта или процесса.

Ключевыми критериями для выбора маркетинговой стратегии и собственно оценки проекта могут быть следующие: ожидаемый вклад в достижение целей программы, в рамках которой осуществляется проект; результативность для целевых групп; соотношение ресурсных затрат (временных, человеческих, финансовых) и результатов; техническая реализуемость; степень отрицательного воздействия на окружающую среду и социальную ситуацию.

В плане проекта необходимо обеспечить соответствие цели задачам, действиям и результатам; четкое распределение ответственности за исполнение; определение сроков и локации действий. Критическим условием внедрения медицинских инноваций является положительное воздействие инновационной активности на динамику региональных социально-экономических показателей. В частности, при разработке проекта инжинирингового центра технологических решений (организация сквозных производств в полностью готовом для использования виде) для предприятий медицинской промышленности были определены ключевые показатели из «Стратегии социально-экономического развития Республики Башкортостан на период до 2030 года» [25], на рост которых повлияет создание инжинирингового центра.

Предложенный алгоритм осуществления социально ориентированного маркетинга инновационных проектов в сфере медицины может быть использован как инвесторами, так и государственными структурами при принятии решения о реализации инвестиционно-инновационных проектов, что обеспечит сокращение сроков принятия решения и повысит качество реализации как самого проекта, так и создаваемого продукта. Но имеются ряд ограничений использования данного алгоритма, которые в обязательном порядке должны быть учтены в процессе управления высокотехнологичными проектами в сфере медицины.

Во-первых, появление прорывных инноваций в сфере медицины, не имеющих аналогов, предполагает отсутствие статистики внедрения и исполь- 
зования, неясность и/или недостаточность информации о преимуществах и отдаленных последствиях применения медицинской инновации. Во-вторых, слабое владение принципами стратегического, инновационного и маркетингового мышления основными участниками проектов в сфере здравоохранения (медицинским персоналом, инженерами-конструкторами, государственными чиновниками). Необходимо изменение инновационного мышления участников всех структур, связанных с производством медицинской продукции и оказанием медицинских услуг для преодоления «порога недоверия» к инновациям. В-третьих, требуется улучшение финансирования системы здравоохранения (в части как производства продукции, так и обслуживания населения).

Потенциальная эффективность реализуемых социально ориентированных и клиентоцентрированных проектов в сфере здравоохранения может быть выражена следующими показателями: рост удовлетворенности населения качеством медицинской помощи; рост удовлетворенности медицинского персонала условиями и технической оснащенностью труда; улучшение производственной, социальной и институциональной инфраструктуры; расширение территориальной доступности медицинской помощи.

Социально ориентированное маркетинговое управление инновационноинвестиционными проектами в сфере здравоохранения предполагает объединение потенциалов представителей различных отраслей научного знания (в области инженерных, экономических, медицинских и социальных наук), бизнеса и государства на принципах взаимовыгодных партнерских, социально ориентированных отношений. Идея усиления взаимодействия института здравоохранения с другими общественными институтами обоснована исследователями [26]. Изменение отношения населения к здоровью связано с воздействием макросоциальных переменных, например, государственной идеологии, центральной идеей которой должна выступать забота о здоровье как конечной цели реализации всех государственных приоритетов [27, с. 30].

Таким образом, позиция авторов заключается в том, что в управлении инновационными проектами в области высокотехнологичной медицины необходимо опираться на концепцию маркетинга взаимоотношений. Подобные проекты неразрывно связаны с состоянием и ожиданиями социальной сферы общества. Акцентирование внимания на взаимоотношениях следует рассматривать как важную предпосылку социально ориентированного маркетингового управления инновационными проектами в сфере медицины, так как члены общества очень чувствительны к качеству своего взаимодействия с другими людьми. Социально ориентированный, клиентоцентрированный маркетинговый подход к инновационным медицинским проектам невозможно реализовать без масштабного государственного присутствия в качестве активного регулятора рыночных отношений в сфере здравоохранения. Именно ориентация в коллаборации государства, общественных организаций, бизнеса на со- 
хранение здоровья и трудоспособности населения способствует обеспечению конкретного человека и социальных групп населения медицинскими товарами и услугами.

Приведенные в статье аргументы позволяют снизить уровень дискуссионности вопроса о маркетинговом управлении проектами в области медицинских инноваций и повысить эффективность принимаемых управленческих решений в этом направлении, что в итоге способно привести к увеличению количества и повышению качества реализованных инновационных проектов.

\section{Список литературы}

1. Стратегия развития здравоохранения в Российской Федерации на период до 2025 года [Электронный ресурс]: утв. Указом Президента Рос. Федерации от 6 июня 2019 г. № 254. - URL: http://docs.cntd.ru/document/554815875 (дата обращения: 06.02.2020).

2. Акопян А.С. Особенности конкуренции на рынке медицинских услуг и товаров медицинского назначения // Маркетинг. - 2011. - № 4. - С. 98-107.

3. Домаков В.В. Теория комплексирования в маркетинге медицинских товаров и услуг. - СПб.: Электронстандарт, 1996. - 313 с.

4. Маркетинг, лизинг, логистика в здравоохранении / Р.А.Галкин, С.И. Двойников, В.В. Павлов, И.В. Поляков, С.А. Уваров. - Самара; СПб.: Перспектива, 1998. - 175 с.

5. Кемалов Р.Ф. Роль маркетинга в здравоохранении // Проблемы социальной гигиены, здравоохранения и истории медицины. - 2006. - № 1. - С. 41-43.

6. Княжев В.А., Можаров Е.А., Романов А.И. Менеджмент и маркетинг медицинских услуг. - М.: Златограф, 2000. - 172 с.

7. Осипова Е.3. Повышение экономической эффективности управления медицинским учреждением // Экономика: вчера, сегодня, завтра. - 2019. - Т. 9, № 5-1. - С. 266-274.

8. Тогунов И.А. Теория управления рынком медицинских услуг. - Владимир: Собор, 2007. - 307 с.

9. Appelt P., Hauser T. Marketing Innovation: Prescribing Innovations: A Practical Framework for Effective Marketing of Medical Device Innovations // Journal of Medical Marketing. - 2006. - Vol. 6, iss. 3. - P. 195-202.

10. Cătoiu I., Geangu Iu. P., Gârdan, D.A. Applying Marketing Principles in the Field of Medical Services an Ethical Challenge? // Procedia Economics and Finance. - 2013. - Vol. 6. - P. 449-456.

11. Formoso G., Marata A.M., Magrini N. Social Marketing: Should It Be Used to Promote Evidence-Based Health Information? // Social Science \& Medicine. - 2007. - Vol. 64, iss. 4. - P. 949-953. 
12. French J. Social Marketing and Public Health: Theory and Practice. - Oxford: Oxford University Press, 2017. - 256 p.

13. Provines Chr.D. Overcoming Organizational Barriers to Implementing Value-Based Pricing in the Medical Devices \& Diagnostics Industry // Journal of Medical Marketing. - 2010. - Vol. 10, iss. 1. - P. 37-44.

14. Siegel M., Doner L. Marketing Public Health: Strategies to Promote Social Change. - Sudbury, MA: Jones \& Bartlett Learning, 2004. - 530 p.

15. Cheng H., Kotler Ph., Lee N. Social Marketing for Public Health: Global Trends and Success Stories. - Sudbury, MA: Jones \& Bartlett Learning, 2010. $422 \mathrm{p}$.

16. Экономика здравоохранения: учеб. пособие / под ред. М.Г. Колосницыной, И.М. Шеймана, С.В. Шишкина. - М.: Изд. дом ГУ ВШЭ, 2008. - 479 с.

17. Gronroos Chr. Quo Vadis Marketing. Towards a Relationship Marketing Paradigm // Journal of Marketing Management. - 1994. - Vol. 10. - P. 347-360.

18. Gummesson E. Total Relationship Marketing: From the 4Ps - Product, Price, Promotion, Place of Traditional Marketing Management to the 30Rs-thirty of the New Marketing Paradigm. - Oxford: Butterworth-Heinemann, 2002. $-350 \mathrm{p}$.

19. Malhotra N., Agarwal J. A Stakeholder Perspective on Relationship Marketing // Journal of Relationship Marketing. - 2002. - Vol. 1, no. 2. - P. 3-37.

20. Йонас Г. Принцип ответственности: Опыт этики для технологической цивилизации / пер. с нем. И.И. Маханькова. - М.: Айрис-пресс, 2004. - 480 с.

21. Making Sustainability Work: Best Practices in Managing and Measuring Corporate Social, Environmental and Economic Impacts / M.J. Epstein, A.R. Buhovac, J. Elkington, H.B.D. Leonard. - London: Routledge, 2017. - 324 p.

22. Касимова Э.Р., Рувенный И.Я. Государственно-частное партнерство в системе финансирования здравоохранения Республики Башкортостан // Менеджмент и маркетинг в различных сферах деятельности: сб. науч. тр. / под ред. У.Г. Зиннурова; УГАТУ. - Уфа, 2018. - С. 130-135.

23. Бикметов Е.Ю., Гумерова З.Ж. Особенности и условия маркетинговоориентированного управления инновационными проектами в области высокотехнологичной медицины // Kant. - 2018. - № 4 (29). - С. 226-229.

24. Бикметов Е.Ю., Рувенный И.Я. Эффективные PR-инструменты на рынке B2B // Актуальные проблемы коммуникации: теория и практика: материалы XI Всерос. науч.-практ. конф. / Башкир. гос. ун-т. - Уфа, 2019. - С. 16-21.

25. Стратегия социально-экономического развития Республики Башкортостан на период до 2030 года [Электронный ресурс]. - URL: https: // economy.bashkortostan.ru/dejatelnost/strategicheskoe-planirovanie/strategiya-razvitiya-respubliki-bashkortostan/strategiya-respubliki-bashkortostan-2030/ (дата обращения: 22.12.2019). 
26. Насибуллин Р.Т. Здравоохранение как социальный институт // Вестник Пермского национального исследовательского политехнического университета. Социально-экономические науки. - 2019. - № 4. - С. 161-173.

27. Судьин С.А. Гендерный аспект социологии медицины и здоровья // Женщина в российском обществе. - 2012. - № 4 (65). - С. 24-31.

\section{References}

1. Strategiia razvitiia zdravookhraneniia v Rossiiskoi Federatsii na period do 2025 goda [Strategy of public health development in the Russian Federation for the period until 2025]. Approved by Decree of the President of the Russian Federation of Jun. 6, 2019 no. 254, available at: http://docs.cntd.ru/document/554815875 (accessed 06 February 2020).

2. Akopian A.S. Osobennosti konkurentsii na rynke meditsinskikh uslug $i$ tovarov meditsinskogo naznacheniia [Features of competition in the market of medical services and medical supplies]. Marketing, 2011, no. 4, pp. 98-107.

3. Domakov V.V. Teoriia kompleksirovaniia $\mathrm{v}$ marketinge meditsinskikh tovarov i uslug [Integration theory in marketing of medical goods and services]. St. Petersburg, Elektronstandart, 1996, 313 p.

4. Galkin R.A., Dvoinikov S.I., Pavlov V.V., Poliakov I.V., Uvarov S.A. Marketing, lizing, logistika $\mathrm{v}$ zdravookhranenii [Marketing, leasing, logistics in healthcare]. Samara, St. Petersburg, Perspektiva, 1998, 175 p.

5. Kemalov R.F. Rol' marketinga v zdravookhranenii [Significance of marketing in public health]. Problemy sotsial'noi gigieny, zdravookhraneniia $i$ istorii meditsiny, 2006, no. 1, pp. 41-43.

6. Kniazhev V.A., Mozharov E.A., Romanov A.I. Menedzhment i marketing meditsinskikh uslug [Management and marketing of medical services]. Moscow, Zlatograf, 2000, $172 \mathrm{p}$.

7. Osipova E.Z. Povyshenie ekonomicheskoi effektivnosti upravleniia meditsinskim uchrezhdeniem [Improvement of economic efficiency of the management of health facilities]. Ekonomika: vchera, segodnia, zavtra, 2019, vol. 9, no. 51, pp. 266-274.

8. Togunov I.A. Teoriia upravleniia rynkom meditsinskikh uslug [Management of healthcare services market]. Vladimir, Sobor, 2007, 307 p.

9. Appelt P., Hauser T. Marketing innovation: Prescribing innovations: A practical framework for effective marketing of medical device innovations. Journal of Medical Marketing, 2006, vol. 6, no. 3, pp. 195-202.

10. Cătoiu I., Geangu Iu. P., Gârdan, D.A. Applying marketing principles in the field of medical services an ethical challenge? Procedia Economics and Finance, 2013, vol. 6, pp. 449-456. 
11. Formoso G., Marata A.M., Magrini N. Social marketing: Should it be used to promote evidence-based health information? Social Science \& Medicine, 2007, vol. 64, no. 4, pp. 949-953.

12. French J. Social marketing and public health: Theory and practice. Oxford, Oxford University Press, 2017, 256 p.

13. Provines Chr. D. Overcoming organizational barriers to implementing value-based pricing in the medical devices \& diagnostics industry. Journal of Medical Marketing, 2010, vol. 10, no. 1, pp. 37-44.

14. Siegel M., Doner L. Marketing public health: Strategies to promote social change. Sudbury, MA. Jones \& Bartlett Learning, 2004, 530 p.

15. Cheng H., Kotler Ph., Lee N. Social marketing for public health: Global trends and success stories. Sudbury, MA. Jones \& Bartlett Learning, 2010, 422 p.

16. Ekonomika zdravookhraneniia [Public health economy]. Ed. M.G. Kolosnitsyna, I.M. Sheiman, S.V. Shishkin. Moscow, Higher School of Economics, 2008, 479 p.

17. Gronroos Chr. Quo Vadis Marketing. Towards a relationship. Marketing paradigm. Journal of Marketing Management, 1994, vol. 10, pp. 347-360.

18. Gummesson E. Total relationship marketing: From the 4Ps - product, price, promotion, Place of traditional marketing management to the 30Rs-thirty - of the new marketing paradigm. Oxford. Butterworth-Heinemann, 2002, $350 \mathrm{p}$.

19. Malhotra N., Agarwal J. A stakeholder perspective on relationship marketing. Journal of Relationship Marketing, 2002, vol. 1, no. 2, pp. 3-37.

20. Jonas H. The imperative of responsibility. In search of an ethics for the technological age (Russ. ed.: Ionas G. Printsip otvetstvennosti: Opyt etiki dlia tekhnologicheskoi tsivilizatsii. Moscow, Airis-press, 2004, 480 p.).

21. Epstein M.J., Buhovac A.R., Elkington J., Leonard H.B.D. Making sustainability work: Best practices in managing and measuring corporate social, environmental and economic impacts. London. Routledge, 2017, 324 p.

22. Kasimova E.R., Ruvennyi I.Ia. Gosudarstvenno-chastnoe partnerstvo v sisteme finansirovaniia zdravookhraneniia Respubliki Bashkortostan [Public-private partnership in the system of public health in the Republic of Bashkortostan]. Menedzhment $i$ marketing $v$ razlichnykh sferakh deiatel'nosti. Ed. U.G. Zinnurov. Ufa, Ufa State Aviation Technical University, 2018, pp. 130-135.

23. Bikmetov E.Iu., Gumerova Z.Zh. Osobennosti i usloviia marketingovoorientirovannogo upravleniia innovatsionnymi proektami $\mathrm{v}$ oblasti vysokotekhnologichnoi meditsiny [Special aspects and modalities of market-friendly innovation project management in high-tech medicine]. Kant, 2018, 4(29), pp. 226-229.

24. Bikmetov E.Iu., Ruvennyi I.Ia. Effektivnye PR-instrumenty na rynke B2B [Effective PR-tools in the B2B market]. Aktual'nye problemy kommunikatsii: teoriia $i$ praktika. Proceedings of XI All-Russ. Sci.-Pract. Conf. Ufa, Bashkir State University, 2019, pp. 16-21. 
25. Strategiia sotsial'no-ekonomicheskogo razvitiia Respubliki Bashkortostan na period do 2030 goda [Strategy of socio-economic development of the Republic of Bashkortostan for the period until 2030]. Available at: https://economy.bashkortostan.ru/dejatelnost/strategicheskoe-planirovanie/strategiya-razvitiya-respubliki-bashkortostan/strategiya-respubliki-bashkortostan-2030/ (accessed 02 December 2019).

26. Nasibullin R.T. Zdravookhranenie kak sotsial'nyi institut [Healthcare as a social institution]. PNRPU Sociology and Economics Bulletin, 2019, no. 4, pp. 161-173.

27. Sud'in S.A. Gendernyi aspekt sotsiologii meditsiny i zdorov'ia [Gender aspect of sociology of medicine and health]. Zhenshchina $v$ rossiiskom obshchestve, 2012, no. 4(65), pp. 24-31.

Оригинальность $86 \%$

Получено 14.02.2020 Принято 10.03.2020 Опубликовано 29.06.2020

E.Yu. Bikmetov, Z.Zh. Gumerova, I.Ya. Ruvenny

\title{
SOCIALLY-ORIENTED MARKETING IN PROJECT MANAGEMENT OF HIGH-TECH MEDICAL INNOVATIONS
}

\begin{abstract}
The article actualizes the need for marketing project management as a tool for innovative development of Russian healthcare. The research is based on the concept of socially oriented marketing and integration of the efforts of medicine, science, business and public administration. The authors see scientifically planned and organized socially oriented marketing management of innovative projects in the field of health care as one of the ways to reduce the duration of the stage of bringing innovations in the field of high-tech medicine to the market. The applicability of the relationship marketing approach in the health sector is justified; the features and risks of step-by-step marketing support for project management in the field of high-tech medicine are revealed; the possibilities of collaboration of participants in their implementation are determined. Focusing on relationships should be considered as an important prerequisite for socially oriented marketing management of innovative projects. Management of medical projects based on relationship marketing needs to be supplemented with a public-private partnership mechanism to enhance synergy. To concretize the proposed tool, we study the features and risks of the stages of marketing support for project management in the field of high-tech medicine. The conclusion is substantiated that a socially oriented, client-centered marketing approach to innovative medical projects cannot be implemented without the state presence as an active regulator of market relations in the health sector. Orientation in collaboration of the state, non-profit organizations and business to preserve the health and working capacity of the population contributes to providing a specific person and social groups with medical goods and services. The results of the study reduce the level of discussion about marketing project management in the field of medical innovations and improve the effectiveness of management decisions in this direction, which can eventually lead to an increase in the number and quality of implemented innovative projects.

Keywords: innovative project management, high-tech medical products and services, healthcare, socially oriented marketing, relationship marketing, customer focus, public-private partnership.
\end{abstract}


Evgeniy Yu. Bikmetov - Doctor of Sociology, Professor, Department of Management and Marketing, Ufa State Aviation Technical University; Chief researcher, Institute of Social-economy Researches, Ufa Federal Research Center of the Russian Academy of Science, e-mail: bicprof@mail.ru.

Zilyara Zh. Gumerova - Candidate of Economic Sciences, Associate Professor, Department of Management and Marketing, Ufa State Aviation Technical University, e-mail: lapa28@ramblerl.ru.

Igor Ya. Ruvenny - Candidate of Economic Sciences, Head of the Department of Management and Marketing, Ufa State Aviation Technical University, e-mail: ruvenny@mail.ru.

Received 14.02.2020 Accepted 10.03.2020 Published 29.06.2020 